\title{
Production, characterization and In vitro antioxidant activities of exopolysaccharide from Weissella cibaria GA44
}

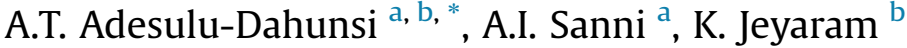 \\ ${ }^{a}$ Department of Microbiology, University of Ibadan, Ibadan, Oyo State, Nigeria \\ ${ }^{\mathrm{b}}$ Microbial Resources Division, Institute of Bioresources and Sustainable Development (IBSD), Imphal, 795001, Manipur, India
}

\section{A R T I C L E I N F O}

\section{Article history:}

Received 5 May 2017

Received in revised form

16 August 2017

Accepted 10 September 2017

Available online 13 September 2017

\section{Keywords:}

Antioxidant

Exopolysaccharides

Gari

Weissella cibaria

FT-IR

\begin{abstract}
A B S T R A C T
Exopolysaccharide (EPS) producing lactic acid bacteria (LAB) strain GA44 isolated from gari (a Nigerian traditional fermented cassava mash) was identified with $16 \mathrm{~S}$ rRNA gene sequencing as Weissella cibaria. The EPS produced mainly composed of glucose and rhamnose sugar units and its molecular mass was about $2.8 \times 10^{5} \mathrm{Da}$. The fourier-transform infrared (FT-IR) spectrum analysis showed characteristics absorption peaks indicating the presence of $-\mathrm{OH}, \mathrm{C}=\mathrm{O}$ and $\mathrm{C}-\mathrm{H}$ groups. Central composite design (CCD) and response surface methodology (RSM) were used to study the interactive effect of the significant factors on EPS yield. Under optimum conditions, the predicted maximum EPS produced $4.88 \mathrm{~g} / \mathrm{L}$ while the actual experimental value was $4.80 \mathrm{~g} / \mathrm{L}$. The in-vitro antioxidant activities of the EPS showed good scavenging effects on superoxide anion radical and hydroxyl radical. The characteristics of this EPS isolated from food source will be useful in food industries and could also serve as a potential antioxidant.
\end{abstract} (๑) 2017 Elsevier Ltd. All rights reserved.

\section{Introduction}

Many LAB are able to produce EPS which are known to improve the physical properties of fermented food products. The increase in demand for the production of polysaccharides by microbes for use in food and pharmaceutical industries has been enormously researched on (Imran et al., 2016; Kajala et al., 2015; Sajna et al., 2013). Exopolysaccharides are economically significant because they can impart functional effects to food and also confer beneficial health effects on human when consumed (Welman \& Maddox, 2003). Polysaccharides with beneficial health effects are widely used in the food industry as gelling, thickening, stabilizing, or emulsifying agents. They play a major role in the rheology and texture of the fermented food products (Dilna, Surya, Aswathy, Varsha, \& Sakthikumar, 2015).

Several functional EPS which are produced from LAB species isolated from various fermented sources have displayed both antioxidant and probiotic properties (Pan \& Mei, 2010; Zhang et al., 2013; Abdhul et al., 2014). Antioxidants have received enormous attention by researchers/scientists due to the increased number of diseases caused by the formation of free radical and/or reactive

\footnotetext{
* Corresponding author. Department of Microbiology, University of Ibadan, Ibadan, Oyo State, Nigeria.

E-mail address: adesuluchemmy@yahoo.com (A.T. Adesulu-Dahunsi).
}

oxygen species (Emerit, Edeas, \& Bricaire, 2004; Kris-Etherton et al., 2002). Reactive oxygen species (ROS) are chemically reactive species containing oxygen, which easily react with other molecules in a cell. They are formed as a natural by-product of the normal metabolism of oxygen and play important roles in cell signaling and homeostasis. Accumulation of these ROS in cells, or their increase as a result of environmental stress may cause damage to DNA, RNA, and proteins, and may even leads to cell death (Melov et al., 2000). Exopolysaccharides from LAB are referred to as natural antioxidants and have been reported safe as they played roles in the maintenance of human health, prevention and treatment of diseases, they may also serve as possible substitutes for the synthetic antioxidants because of the toxicity effect the latter displays (Li et al., 2013; Liu, Ooi, \& Chang, 1997).

Researchers have reported that Weissella species can produce significant amount of EPS (Badel, Bernardi, \& Michaud, 2011; Kajala et al., 2015). W. cibaria have been isolated from plants and vegetables, and also from different indigenous fermented foods of Nigeria such as gari, fufu, ogi (Adesulu-Dahunsi, Sanni, \& Jeyaram, 2017). Weissella sp. have the ability to produce significant amounts of non-digestible oligosaccharides and extracellular polysaccharides which can be used as prebiotics or for other applications in food industries (Baruah, Maina, Katina, Juvonen, \& Goyal, 2017; Malang, Maina, Schwab, Tenkanen, \& Lacroix, 2015). Some LAB strains utilizes the fermentable sugars for the 
biosynthesis of EPS. Sugars such as glucose, lactose, sucrose and mannose serve as carbon sources (Patel, Majumder, \& Goyal, 2012; Xu, Ma, Wang, Liu, \& Li, 2010).

The LAB producing strain, growth medium and culture conditions may influence the EPS production and their monomer compositions (De Vuyst \& Degeest, 1999; Degeest, Vaningelgem, \& De Vuyst, 2001). Similarly, the quantity of EPS produced by different strains of LAB varies considerably (Badel et al., 2011; Laws \& Marshall, 2001). Response surface methodology has recently been used for modeling and optimization of processes such as fermentation media, process and cultivation conditions for EPS production (Imran et al., 2016; Raza, Makeen, Wang, Xu, \& Qirong, 2011). In this paper, $W$. cibaria GA44 isolated from gari was screened and identified to produce appreciable amounts of exopolysaccharide in modified MRS-sucrose media. The EPS was purified, the chemical properties determined and its functional groups were detected by infrared spectrophotometry. Response surface methodology was used to determine the optimal conditions for the EPS yield. The antioxidant activities were also investigated using various in vitro assays such as 1,1-diphenyl-2-picryl-hydrazyl (DPPH) free radical scavenging activity, reducing power assay, superoxide anion and hydroxyl radical scavenging activity in order to understand the potential usefulness of the EPS from the indigenous fermented food as a natural antioxidant.

\section{Materials and methods}

\subsection{Microorganism and reagents}

Exopolysaccharide producing LAB strain W. cibaria GA44, isolated from gari was identified according to its morphological characteristics and 16S rRNA sequence analysis. The nucleotide sequence was submitted to the GenBank under the nucleotide accession number; KU892397. The culture was grown in Man Rogosa and Sharpe (MRS) medium at $30^{\circ} \mathrm{C}$ for $48 \mathrm{~h}$ and maintained on the agar at $4{ }^{\circ} \mathrm{C}$. T-series dextrans were purchased from Pharmacia Co. ltd. (Uppsala, Sweden), DPPH, trichloroacetic acid (TCA), trifluoroacetic acid (TFA), bovine serum albumin (BSA), phenol, concentrated sulfuric acid, pyrogallol, Folin-Ciocalteuvd reagent, methanol, ferric chloride, potassium ferricyanide, glucose, galactose, fructose, mannose, D-glucuronic acid, rhamnose, xylose and standard antioxidant compound ascorbic acid were all purchased from Sigma chemical co. ltd. (St. Louis, USA). All other reagents used were of analytical grade.

\subsection{Partial purification of the EPS}

The EPS was extracted, isolated and purified following the method described by Savadogo et al. (2004), with slight modifications. Weissella cibaria GA44 was incubated at $30^{\circ} \mathrm{C}$ for $24 \mathrm{~h}$ in MRS broth, $100 \mathrm{~mL}$ of the culture was inoculated into $900 \mathrm{~mL}$ modified MRS ( $m$-MRS) broth (glucose was replaced with sucrose as carbon source at a concentration of $20 \mathrm{~g} / \mathrm{L}$ ) and was incubated in an incubator shaker. After $24 \mathrm{~h}$, the cultures were heated at $100{ }^{\circ} \mathrm{C}$ for $10 \mathrm{~min}$ to inactivate enzymes potentially capable of polymer degradation and the cells were removed by centrifugation at $12,000 \times \mathrm{g}$ for $15 \mathrm{~min}$ at $4{ }^{\circ} \mathrm{C}$. The supernatant was precipitated with double volume chilled ethanol, shaken vigorously and centrifuged at $5000 \times \mathrm{g}$ for $30 \mathrm{~min}$ at $4{ }^{\circ} \mathrm{C}$. The precipitate was dried at $50{ }^{\circ} \mathrm{C}$.

Finally, the precipitate was dissolved in ultrapure water, and was again precipitated with double volume of chilled ethanol, this step was repeated three times and dialyzed against distilled water for 2 day at $4{ }^{\circ} \mathrm{C}$ using $10 \mathrm{kDa}$ dialysis membrane with the changing of the water twice daily and then lyophilized. Freeze-dried EPS was used for further characterization.

\subsection{Estimation of total sugar and protein content}

The total sugar content of the EPS was determined by phenolsulfuric acid method (Dubois, Gilles, Hamilton, Rebers, \& Smith, 1956). The total protein content was determined by Folin's Lowry method (Lowry, Rosebrough, Farr, \& Randall, 1951).

\subsection{Molecular mass determination}

The molecular mass of the EPS was determined on high performance liquid chromatography (HPLC) system (Agilent 1100) equipped with a TSK-GEL G3000SWxl column $(7.5 \times 300 \mathrm{~mm}$, Tosoh Corp. Tokyo, Japan) and a refractive index detector (RID). The column was eluted with $0.1 \mathrm{M} \mathrm{Na}_{2} \mathrm{SO}_{4}$ solution at a flow rate of $0.8 \mathrm{~mL} \mathrm{~min}^{-1}$. Molecular mass was estimated from the standard graph which was plotted using standard dextrans (Sigma-Aldrich, USA).

\subsection{Fourier transform infrared (FT-IR) spectroscopy}

The functional groups of the purified EPS were detected by FT-IR spectroscopy. The sample pellet was prepared by grinding a mixture of the EPS ( $1 \mathrm{mg}$ ) with $100 \mathrm{mg}$ of dry $\mathrm{KBr}$ powder, followed by pressing the mixture into the mold. FTIR spectra was recorded on a Thermo Nicolet 6700 instrument in the ranges of $400-4000 \mathrm{~cm}^{-1}$.

\subsection{Monosaccharide composition analysis of EPS}

The monosaccharide composition of the EPS was analyzed. The EPS was hydrolysed by adding $5 \mathrm{mg}$ of the EPS sample to $0.5 \mathrm{~mL}$ of $6 \mathrm{~N}$ trifluoroacetic acid (TFA) at $100{ }^{\circ} \mathrm{C}$ for $2 \mathrm{~h}$, the TFA was then removed by evaporation under $\mathrm{N}_{2}$ gas. After hydrolysis, $2 \mu \mathrm{l}$ of the hydrolyzate EPS sample and seven standard sugars (glucose, galactose, fructose, mannose, D-glucuronic acid, rhamnose and xylose) were spotted each onto a silica gel coated aluminum TLC plates. The mixed solvent system n- butanol, ethanol and water (50:30:20 (v/v/v)) were used for separation of carbohydrates and standards and were developed in the TLC chamber, the TLC plate was dried and developed by dipping it into anisaldehyde-sulfuric acid reagent and heating in an oven at $110{ }^{\circ} \mathrm{C}$ for $30 \mathrm{~min}$ (Seo et al., 2014).

\subsection{Effect of culture conditions and the media compositions}

Initial screening for maximum EPS production was carried out by detecting the influence of different carbon and nitrogen sources. Twenty-four (24) hours old culture was inoculated into the media components at different $\mathrm{pH}$, cultivation time and temperatures. The EPS yield and cell growths were evaluated.

\subsection{RSM optimization for enhanced EPS production}

Based on the results obtained from the screening of the culture parameters and media compositions, the CCD was used to find the optimal values for these significant variables, cultivation time, sucrose concentration, yeast extract, $\mathrm{pH}$ and to understand the relationship between these factors and EPS production. A multiple regression analysis of the data was carried out with the statistical Design-Expert ${ }^{\mathbb{B}}$, version 8.0.7.1 package (Stat Ease Inc. Minneapolis, USA). 


\subsection{Assay of antioxidant activities}

\subsubsection{DPPH radical scavenging assay}

The DPPH radical scavenging activity was measured by using the method described by Rai et al. (2011). Briefly, $2.0 \mathrm{~mL}$ DPPH radical solution $(0.16 \mathrm{mM})$ was added to $1.0 \mathrm{~mL}$ sample solution $(0.5-4 \mathrm{mg} / \mathrm{mL})$, and then $2.0 \mathrm{~mL}$ of deionized water was added. The mixture was mixed vigorously and incubated at $37{ }^{\circ} \mathrm{C}$ in the dark for $30 \mathrm{~min}$. The absorbance was measured at $517 \mathrm{~nm}$ against the blank. Methanol with DPPH served as a positive control. The sample blank was prepared by replacing DPPH with methanol.

The DPPH radical (\%) scavenging activity was estimated by the following equation:

$1-\frac{[\text { Asample }- \text { Ablank }]}{\text { Acontrol }} \times 100$

\subsubsection{Reducing power potential}

The reducing power potential of the EPS sample at different concentration levels $(0.5-4 \mathrm{mg} / \mathrm{mL})$ was measured using the method described by Balakrishnan et al. (2011). To $100 \mu \mathrm{L}$ of the EPS sample, $900 \mu \mathrm{L}$ of phosphate buffer $(0.2 \mathrm{M}, \mathrm{pH} 6.6)$ and $900 \mu \mathrm{L}$ of $1 \%$ potassium ferric cyanide are added, and was incubated at $50{ }^{\circ} \mathrm{C}$ for $20 \mathrm{~min} .900 \mu \mathrm{L}$ of $10 \mathrm{Q} \%$ TCA was added, mixed and centrifuged at $5000 \times \mathrm{g}$ for $15 \mathrm{~min}$ and $900 \mu \mathrm{L}$ of the supernatant solution was mixed with $900 \mu \mathrm{L}$ of distilled water and $900 \mu \mathrm{L}$ of $0.1 \%$ ferric chloride. The solution was mixed and the absorbance was taken at $700 \mathrm{~nm}$.

\subsubsection{Superoxide radical scavenging activity}

Super oxide scavenging property of the EPS sample was determined according to the method described by Balakrishnan et al. (2011). To $0.3 \mathrm{~mL}$ of the EPS sample at different concentration levels $(0.5-4 \mathrm{mg} / \mathrm{mL}), 2.6 \mathrm{~mL}$ of $50 \mathrm{mM}$ phosphate buffer $(\mathrm{pH} 8.2$ ) was added and to this $90 \mu \mathrm{L}$ of freshly prepared $3 \mathrm{mM}$ pyrogallol dissolved in $10 \mathrm{mM} \mathrm{HCl}$ was added. Then the absorbance was measured from 0 min to 10 th $\min$ at $325 \mathrm{~nm}$. To $0.3 \mathrm{~mL}$ of distilled water, $2.6 \mathrm{~mL}$ phosphate buffer ( $50 \mathrm{mM}(\mathrm{pH} \mathrm{8.2)})$ was added and this served as blank.

The superoxide scavenging activity (\%) was estimated by the following equation:

$$
1-\frac{\left[\mathrm{A}_{10}-\mathrm{A}_{0}\right]}{\mathrm{C}_{10}-\mathrm{C}_{0}} \times 100
$$

$A_{0}$ and $A_{10}$ are the absorbance of the EPS sample at 0 and 10 min $C_{0}$ and $C_{10}$ are the absorbance of the control at 0 and $10 \mathrm{~min}$.

\subsubsection{Assay of hydroxyl radical scavenging activity}

The hydroxyl radical scavenging effect of the EPS sample was measured with the Fenton reaction. Briefly, the reaction mixture contained $1.0 \mathrm{~mL}$ of brilliant green $(0.435 \mathrm{mM}), 2.0 \mathrm{~mL}$ of $\mathrm{FeSO}_{4}$ $(0.5 \mathrm{mM})$ and $1.5 \mathrm{~mL}$ of $\mathrm{H}_{2} \mathrm{O}_{2}(3.0 \%, \mathrm{w} / \mathrm{v})$. One (1) $\mathrm{mL}$ of the sample at various concentrations $(0.5-4 \mathrm{mg} / \mathrm{mL})$ were added and was incubated at room temperature for $20 \mathrm{~min}$, and the absorbance was measured at $624 \mathrm{~nm}$ (Balakrishnan et al., 2011).

The hydroxyl radical scavenging activity (\%) was estimated by the following equation:

$$
\frac{\left[A_{S}-A_{0}\right]}{A-A_{0}} \times 100
$$

$A_{S}=$ Absorbance of the sample

$A_{0}=$ Absorbance of the control

$\mathrm{A}=$ Absorbance of deionized water without the sample and Fenton reaction

\subsection{Statistical analysis}

All experiments were performed in triplicates and the results represented by their mean \pm SD (standard deviation). Tests of significant differences were determined by Duncan's Multiple Range Test at $(\mathrm{P}<0.05)$.

\section{Results and discussion}

\subsection{Estimation of total sugar and protein content}

The total sugar content in EPS was estimated to be $84.60 \%$. Wang, Zhao, Tian, Yang, and Yang (2015) and Imran et al. (2016) also

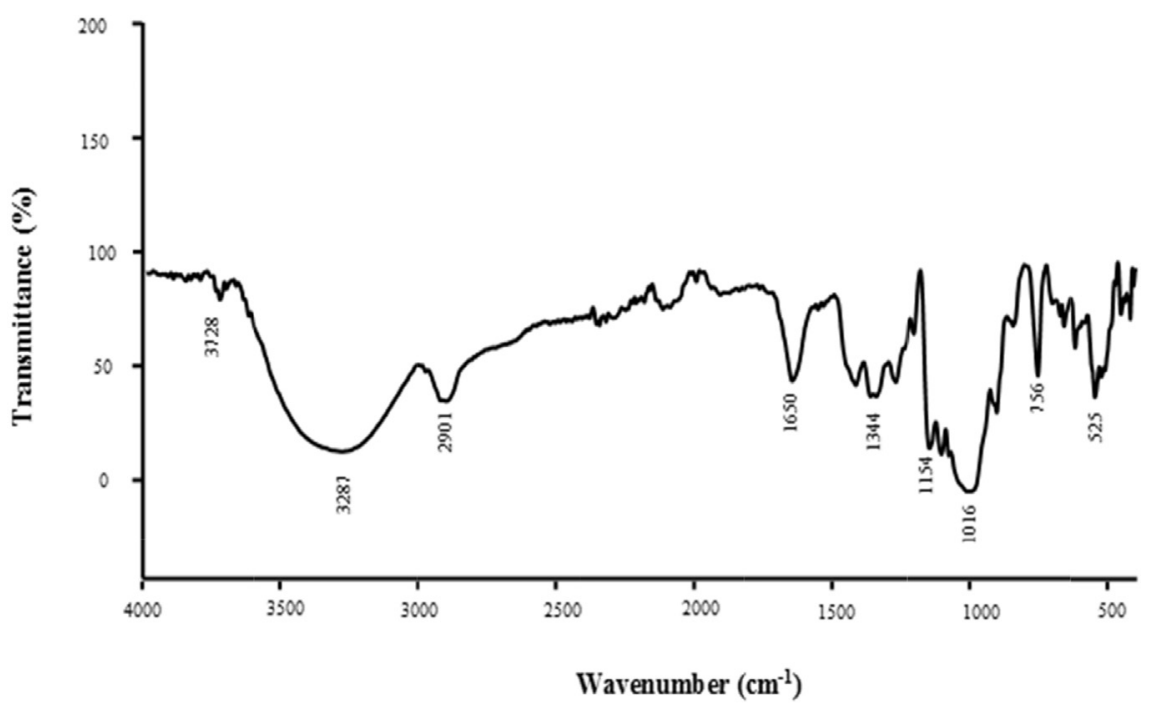

Fig. 1. FTIR spectrum of EPS produced by Weissella cibaria GA44. 
Table 1

Effects of carbon source, nitrogen sources and yeast extract on cell growth and EPS production by Weissella cibaria GA44.

\begin{tabular}{lll}
\hline Culture conditions & Growth $(\mathrm{OD} 600 \mathrm{~nm})$ & $\mathrm{EPS}(\mathrm{g} / \mathrm{L})$ \\
\hline Carbon sources $(\mathbf{2 0} \mathbf{g} / \mathbf{L})$ & & \\
Glucose & $1.462 \pm 0.08$ & $2.87 \pm 0.02$ \\
Sucrose & $1.565 \pm 0.06$ & $3.82 \pm 0.03$ \\
Lactose & $1.432 \pm 0.04$ & $2.21 \pm 0.14$ \\
Galactose & $1.501 \pm 0.01$ & $3.01 \pm 0.17$ \\
Sucrose conc. $(\mathbf{g} / \mathbf{L})$ & & \\
10 & $1.435 \pm 0.02$ & $3.00 \pm 0.12$ \\
20 & $1.668 \pm 0.04$ & $3.80 \pm 0.08$ \\
30 & $1.559 \pm 0.07$ & $2.90 \pm 0.06$ \\
40 & $1.413 \pm 0.09$ & $1.10 \pm 0.04$ \\
50 & $1.332 \pm 0.01$ & $0.87 \pm 0.07$ \\
Nitrogen sources $(\mathbf{2 5} \mathbf{g} / \mathbf{L})$ & & \\
Yeast extract & $1.765 \pm 0.08$ & $3.64 \pm 0.02$ \\
Beef extract & $0.897 \pm 0.15$ & $2.51 \pm 0.04$ \\
Tryptone & $1.332 \pm 0.06$ & $3.01 \pm 0.06$ \\
Peptone & $1.257 \pm 0.01$ & $3.22 \pm 0.10$ \\
Yeast extract conc. $(\%, \mathbf{w} / \mathbf{v})$ & & \\
1.0 & $1.340 \pm 0.02$ & $2.18 \pm 0.11$ \\
1.5 & $1.323 \pm 0.07$ & $2.32 \pm 0.06$ \\
2.0 & $1.408 \pm 0.04$ & $3.07 \pm 0.01$ \\
2.5 & $1.442 \pm 0.03$ & $3.60 \pm 0.11$ \\
3.0 & $1.556 \pm 0.02$ & $3.53 \pm 0.11$ \\
\hline
\end{tabular}

Data are means \pm SD of triplicates.


Temperature $\left({ }^{\circ} \mathrm{C}\right)$ reported high sugar content greater than $90.00 \%$ from EPS produced from LAB. The EPS exhibited a low total protein content of approximately $1.12 \%$. Similarly, other researchers have reported low protein content from purified EPS samples. Liu, Wang, Lin, \& Lin, 2002 reported 2.30\% protein from EPS obtained from the fermentation of kefir grains in soya milk.

\subsection{Molecular mass of EPS}

The molecular mass of EPS was determined by HPLC with size exclusion column. Based on the calibration curve of the elution time of various standard dextrans (Fig. S1 of Supplementary material), the molecular mass of EPS was estimated to be $2.8 \times 10^{5} \mathrm{Da}$.

\subsection{Fourier transform infrared (FT-IR) spectroscopy}

FT-IR is an effective tool for detecting the structural and functional groups in EPS (Wang, Zhang, Zhang, \& Li, 2008). Fig. 1 showed the absorption bands of EPS-GA44 as determined by FTIR spectrum. The broad stretching peak of $32287 \mathrm{~cm}^{-1}$ observed describe the characteristics of a carbohydrate ring and the absorption of this region revealed that EPS contains rounded trait typical of hydroxyl groups which shows that the EPS sample is a polysaccharide. The bands in the $2901 \mathrm{~cm}^{-1}$ region are due to $\mathrm{C}-\mathrm{H}$ - 
Table 2a

Central Composite Design matrix of four variables showing the predicted and actual values of production of exopolysaccharides from Weissella cibaria GA44.

\begin{tabular}{|c|c|c|c|c|c|c|}
\hline \multirow[t]{2}{*}{ Run } & \multirow{2}{*}{$\frac{\mathrm{X}_{1}}{\text { Cultivation time }}$} & \multirow{2}{*}{$\frac{\mathrm{X}_{2}}{\text { Sucrose concentration }(\mathrm{g})}$} & \multirow{2}{*}{$\frac{\mathrm{X}_{3}}{\text { Yeast extract (\%) }}$} & \multirow{2}{*}{$\frac{\mathrm{X}_{4}}{\mathrm{pH}}$} & \multicolumn{2}{|c|}{ EPS Yield (g/L) } \\
\hline & & & & & Actual & Predicted \\
\hline 1 & 48.50 & 20.00 & 2.00 & 8.00 & 4.41 & 4.44 \\
\hline 2 & 49.00 & 20.00 & 2.50 & 7.50 & 4.80 & 4.88 \\
\hline 3 & 47.50 & 18.00 & 2.60 & 7.00 & 4.80 & 4.78 \\
\hline 4 & 46.01 & 16.00 & 3.00 & 6.00 & 4.31 & 4.29 \\
\hline 5 & 46.08 & 24.00 & 1.70 & 6.00 & 4.35 & 4.37 \\
\hline 6 & 46.00 & 24.00 & 2.40 & 8.00 & 4.81 & 4.79 \\
\hline 7 & 49.00 & 24.00 & 2.60 & 6.00 & 4.22 & 4.30 \\
\hline 8 & 46.00 & 17.00 & 1.93 & 5.00 & 4.01 & 4.00 \\
\hline 9 & 48.70 & 24.00 & 2.05 & 6.00 & 4.35 & 4.37 \\
\hline 10 & 48.84 & 19.96 & 2.52 & 5.60 & 4.80 & 4.82 \\
\hline 11 & 48.36 & 22.93 & 2.48 & 7.55 & 4.83 & 4.85 \\
\hline 12 & 48.22 & 21.91 & 2.38 & 6.00 & 4.60 & 4.62 \\
\hline 13 & 48.78 & 20.02 & 2.70 & 6.05 & 4.43 & 4.50 \\
\hline 14 & 46.32 & 20.11 & 2.55 & 7.51 & 4.86 & 4.87 \\
\hline 15 & 46.08 & 18.35 & 1.86 & 6.07 & 3.98 & 4.00 \\
\hline 16 & 45.69 & 16.39 & 2.47 & 7.51 & 4.55 & 4.46 \\
\hline 17 & 47.01 & 19.05 & 2.58 & 6.41 & 3.99 & 4.02 \\
\hline 18 & 46.59 & 18.77 & 1.78 & 6.45 & 4.05 & 4.00 \\
\hline 19 & 46.08 & 22.35 & 2.38 & 7.02 & 4.32 & 4.35 \\
\hline 20 & 47.69 & 22.81 & 3.00 & 6.30 & 4.07 & 4.10 \\
\hline 21 & 47.01 & 23.31 & 2.80 & 7.85 & 4.11 & 4.10 \\
\hline 22 & 48.59 & 18.38 & 1.00 & 6.55 & 3.87 & 3.90 \\
\hline 23 & 46.72 & 16.81 & 3.00 & 7.14 & 4.05 & 4.10 \\
\hline 24 & 47.17 & 23.41 & 2.65 & 6.57 & 4.12 & 4.10 \\
\hline 25 & 48.16 & 21.37 & 2.86 & 6.63 & 4.09 & 4.05 \\
\hline 26 & 48.32 & 16.21 & 1.92 & 6.80 & 4.11 & 4.12 \\
\hline 27 & 45.00 & 20.04 & 2.51 & 7.32 & 4.67 & 4.70 \\
\hline 28 & 46.00 & 20.42 & 1.26 & 5.67 & 3.22 & 3.40 \\
\hline 29 & 46.91 & 21.62 & 2.77 & 6.04 & 3.75 & 3.80 \\
\hline 30 & 47.66 & 22.40 & 3.00 & 7.11 & 4.19 & 4.20 \\
\hline
\end{tabular}

stretching vibration, and the bands around $1650 \mathrm{~cm}^{-1}$ correspond to $\mathrm{C}=\mathrm{O}$ and carboxyl group. The absorption band at $1344 \mathrm{~cm}^{-1}$ represents the stretching vibration of the esters and ether groups. The strong absorption at $1154 \mathrm{~cm}^{-1}$ was dominated by glycosidic linkage $(\mathrm{C}-\mathrm{O}-\mathrm{C})$-stretching vibration. The presence of different functional groups revealed a typical heteropolymeric nature of the EPS sample. The configuration of polysaccharides fraction determined using FT-IR spectroscopy have been reported by other researchers (Liu et al., 2010; Imran et al., 2016).

\subsection{Monosaccharide composition analysis of EPS}

The EPS sample showed two distinguishable sugar spots on the TLC plate. Based on their retention force $(R f)$ values when compared with the standard sugars, they were identified as glucose and rhamnose. The presence of different sugar moieties suggests that the EPS is an heteropolysaccharide. Baruah et al. (2017) reported the EPS produced by Weissella cibaria RBA12 was composed of only glucose unit. Fukuda et al. (2009) also reported that EPS from

Table 2b

Analysis of Variance (ANOVA) of quadratic model for production of exopolysaccharide in Weissella cibaria GA44.

\begin{tabular}{|c|c|c|c|c|c|c|}
\hline Source & Sum of Squares & df & Mean Square & F Value & $\begin{array}{l}\text { p-value } \\
\text { Prob > F }\end{array}$ & \\
\hline Model & 1.35 & 14 & 0.74 & 7.07 & 0.0003 & Significant \\
\hline A-Cultivation time & 0.023 & 1 & 0.023 & 1.73 & 0.2088 & \\
\hline B-Sucrose conc. & 3.375 & 1 & 3.375 & 0.025 & 0.8769 & \\
\hline C-Yeast extract & 0.085 & 1 & 0.085 & 6.27 & 0.0243 & \\
\hline $\mathrm{D}-\mathrm{Ph}$ & 1.504 & 1 & 1.504 & 0.11 & 0.7439 & \\
\hline $\mathrm{AB}$ & 0.013 & 1 & 0.013 & 0.93 & 0.3497 & \\
\hline$A C$ & 0.083 & 1 & 0.083 & 6.08 & 0.0262 & \\
\hline $\mathrm{AD}$ & 0.019 & 1 & 0.019 & 1.39 & 0.2565 & \\
\hline BC & 7.656 & 1 & 7.656 & 0.56 & 0.4644 & \\
\hline $\mathrm{BD}$ & 0.039 & 1 & 0.039 & 2.87 & 0.1108 & \\
\hline $\mathrm{CD}$ & 1.806 & 1 & 1.806 & 0.13 & 0.7205 & \\
\hline$A^{2}$ & 0.030 & 1 & 0.030 & 2.20 & 0.1586 & \\
\hline $\mathrm{B}^{2}$ & 0.48 & 1 & 0.48 & 35.06 & $<0.0001$ & \\
\hline$C^{2}$ & 0.61 & 1 & 0.61 & 44.99 & $<0.0001$ & \\
\hline $\mathrm{D}^{2}$ & 0.27 & 1 & 0.27 & 19.90 & 0.0005 & \\
\hline Residual & 0.20 & 15 & 0.20 & & & \\
\hline Lack of Fit & 0.12 & 10 & 0.12 & 0.67 & 0.7246 & not significant \\
\hline Pure Error & 8.087 & 5 & 5.13 & & & \\
\hline Cor Total & 1.55 & 29 & & & & \\
\hline
\end{tabular}

R-Squared $=0.8602 ;$ Adequate Precision $=8.691$. 
L. fermentum TDS030603 contained glucose and galactose using TLC technique.

\subsection{Effect of culture conditions and media composition on EPS production}

The effect of different carbon and nitrogen sources on EPS yield and cell growth was investigated in MRS broth (Table 1). Sucrose was found to be the best carbon source for EPS production $(3.82 \pm 0.03 \mathrm{~g} / \mathrm{L})$. Examining the different concentration levels of sucrose $(10-50 \mathrm{~g} / \mathrm{L})$, the optimum EPS yield and cell growth was $3.80 \pm 0.08 \mathrm{~g} / \mathrm{L}(\mathrm{OD} 6001.668 \pm 0.04)$ at $20 \mathrm{~g} / \mathrm{L}$. Moreover, decrease in cell growth and EPS yield were observed at sucrose concentration more than 20 g/L. Similarly, Kim, Robyt, Lee, Lee, and Kim (2003) and Sarwat, Aman, and Ahmed (2008) reported that increase in sucrose concentration results in high EPS yield. The effect of different nitrogen sources on EPS production by W. cibaria GA44 showed yeast extract as the best nitrogen source with the optimum EPS yield and highest cell growth of $3.64 \pm 0.02$, OD600 $1.765 \pm 0.08$. This may be due to the presence of larger quantities of free amino acids and short peptides in the yeast extract. At various concentration of yeast extract, maximum EPS was produced at $2.5 \%$ $(3.60 \pm 0.11 \mathrm{~g} / \mathrm{L})$. EPS production by LAB is greatly influenced by nitrogen sources (Ismail \& Nampoothiri, 2010; Liu et al., 2009; Wang et al., 2010).

The effect of initial $\mathrm{pH}$, different temperature and cultivation time for EPS production and cell growth by W. cibaria GA44 for $\mathrm{pH}$ (6.0-8.0), temperature $\left(20-40^{\circ} \mathrm{C}\right)$ and cultivation time $(12-96 \mathrm{~h})$ were analyzed in MRS broth (Fig. 2). The optimal pH, temperature and cultivation time for cell growth and EPS production were 7.0, $30{ }^{\circ} \mathrm{C}$ and $48 \mathrm{~h}$, respectively with the corresponding cell growth $($ OD600 $1.71 \pm 0.02,1.61 \pm 0.05$ and $1.62 \pm 0.02)$ and EPS $(\mathrm{g} / \mathrm{L})$ production $(3.63 \pm 0.10,3.39 \pm 0.12$ and $3.58 \pm 0.34)$. The quantity of the EPS produced is dependent on the microorganisms and their

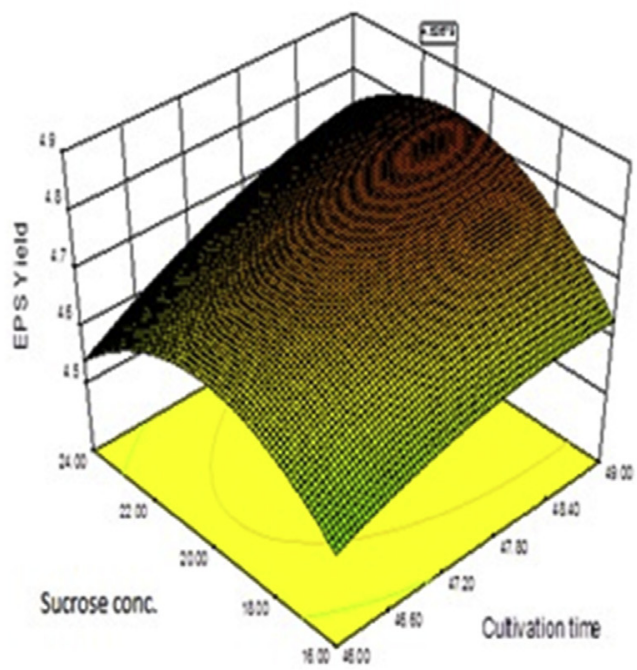

$\mathbf{A}$


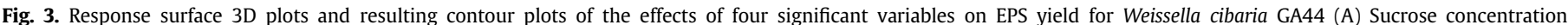

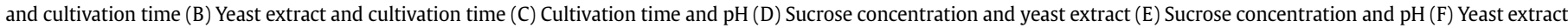
and $\mathrm{pH}$. 
culture conditions such as temperature and pH (Wang et al., 2010). The optimum temperature ranges for EPS yield from LAB have been reported to be $25-35{ }^{\circ} \mathrm{C}$. Ismail and Nampoothiri (2010) and Kanmani et al. (2011) have reported the maximum EPS production by L. plantarum MTCC 9510 and S. phocae P180 at $35^{\circ} \mathrm{C}$. Optimum $\mathrm{pH}$ values ranging between 6.5 and 7.5 have been reported (Kanmani et al., 2011; Raza et al., 2011). Researchers have also reported that during prolonged cultivation time, the yield of EPS decreased gradually (Hallemeersch, De Baet, \& Vandamme, 2002, pp. 407-429; Sarwat et al., 2008).

\section{6. $R S M$ for EPS production}

To determine the optimum combination of the significant factors (sucrose, yeast extract and incubation time) in the medium, the CCD of RSM was employed. There was a total of thirty experimental runs based on the model generated by the software, each in triplicates (Table 2a). The experimental data were statistically analyzed using the Fischer's statistical test for analysis of variance (ANOVA) and the 3D graphs were designed. Table $2 \mathrm{~b}$ showed that the ANOVA for the model, the model p-value of 0.0003 was significant. The model was further confirmed significant with a model F-value of 7.07. The adequate precision measures the signal to noise ratio and the ratio of 8.691 obtained indicates an adequate signal that the model can be used to navigate the design space since a ratio greater than 4 is desirable for the precision of a model. The lack-of-fit term was greater than 0.05 which is non-significant relative to the pure error, in this case nonsignificant lack of fit is good. Hence, $\mathrm{X}_{3}, \mathrm{X}_{1} \mathrm{X}_{3}, \mathrm{X}_{2}^{2}, \mathrm{X}_{3}^{2}, \mathrm{X}_{4}^{2}$ are the significant model terms. The polynomial equation derived on the basis of the experimental factors, and the interactions among the factors is shown below:
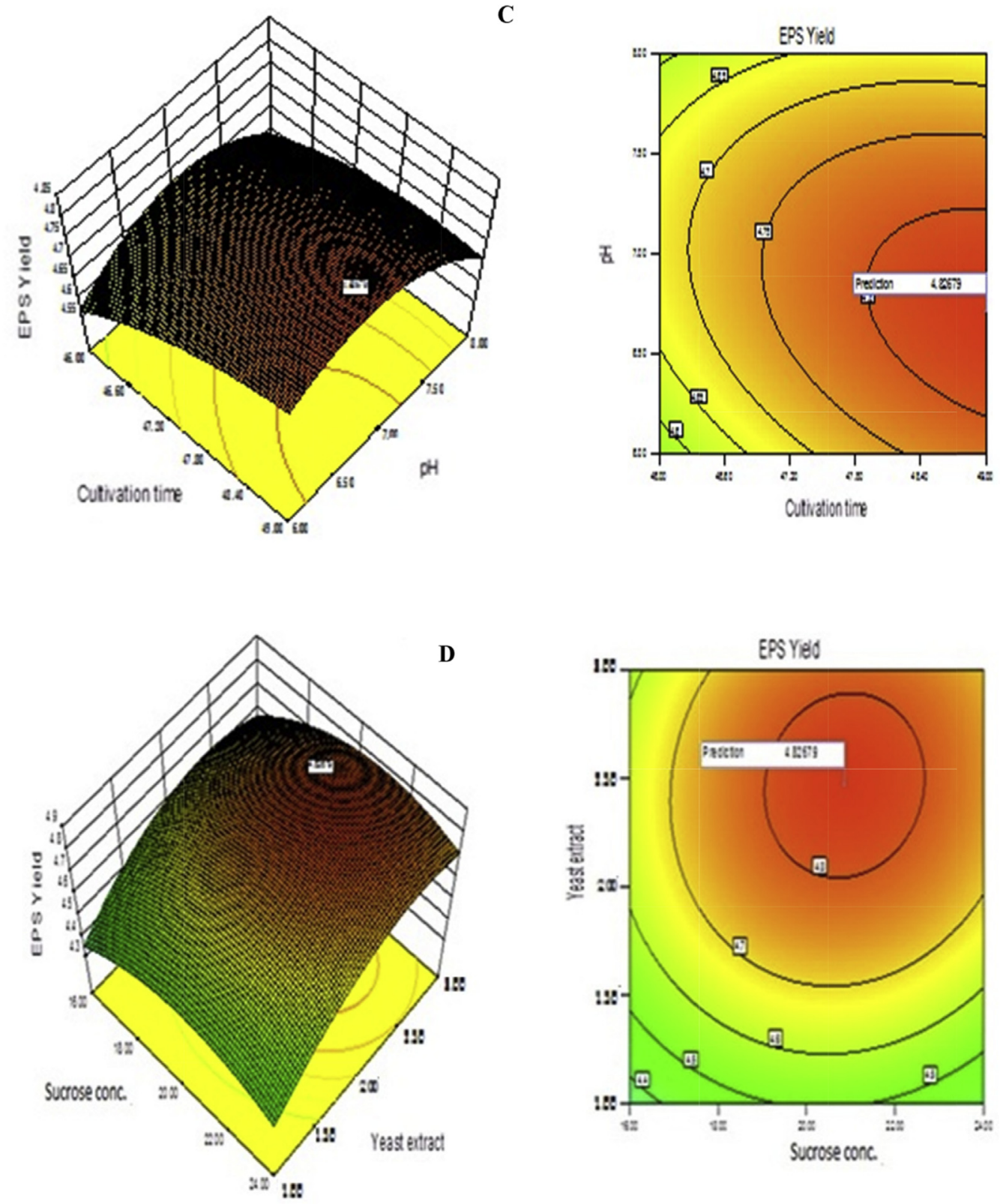

Fig. 3. (continued). 


$$
\begin{aligned}
\mathrm{Y}= & +4.79+0.031 \mathrm{X}_{1}+3.750 \mathrm{X}_{2}+0.060 \mathrm{X}_{3}-7.917 \mathrm{X}_{4} \\
& +0.028 \mathrm{X}_{1} \mathrm{X}_{2}+0.072 \mathrm{X}_{1} \mathrm{X}_{3}-0.034 \mathrm{X}_{1} \mathrm{X}_{4}+0.022 \mathrm{X}_{2} \mathrm{X}_{3} \\
& -0.049 \mathrm{X}_{2} \mathrm{X}_{4}-0.011 \mathrm{X}_{3} \mathrm{X}_{4}-0.033 \mathrm{X}_{1}^{2}-0.13 \mathrm{X}_{2}^{2} \\
& -0.15 \mathrm{X}_{3}^{2}-0.099 \mathrm{X}_{4}^{2}
\end{aligned}
$$

where $\mathrm{Y}=$ is the EPS yield $(\mathrm{g} / \mathrm{L})$.

$\mathrm{X}_{1}, \mathrm{X}_{2}, \mathrm{X}_{3}$ and $\mathrm{X}_{4}$ are the coded values of the test variables: cultivation time $(\mathrm{h})$, sucrose concentration $(\mathrm{g} / \mathrm{L})$, yeast extract $(\%)$ and $\mathrm{pH}$. The response of the RSM was shown as 3D response surface graphs and the combinations of the two factors selected keeping the other constant (Fig. 3). The curvatures' nature of 3D surfaces gave good interaction between sucrose concentration and cultivation time, yeast extract and cultivation time, cultivation time and $\mathrm{pH}$, sucrose concentration and yeast extract, sucrose concentration and $\mathrm{pH}$, yeast extract and $\mathrm{pH}$. The optimal values of the tested variables was cultivation time of $49.00 \mathrm{~h}$; sucrose concentration of $20.00 \mathrm{~g} / \mathrm{L}$; yeast extract of $2.50 \%$ and $\mathrm{pH}$ of 7.50 . Under these conditions, the maximum predicted yield of EPS was $4.88 \mathrm{~g} / \mathrm{L}$ and its experimental (actual) yield was $4.80 \mathrm{~g} / \mathrm{L}$. Several researchers have studied the production of EPS in varying media and production conditions (Macedo, Lacroix, Gardner, \& Champagne, 2002; Shene \& Bravo, 2007). The results obtained in this present study showed

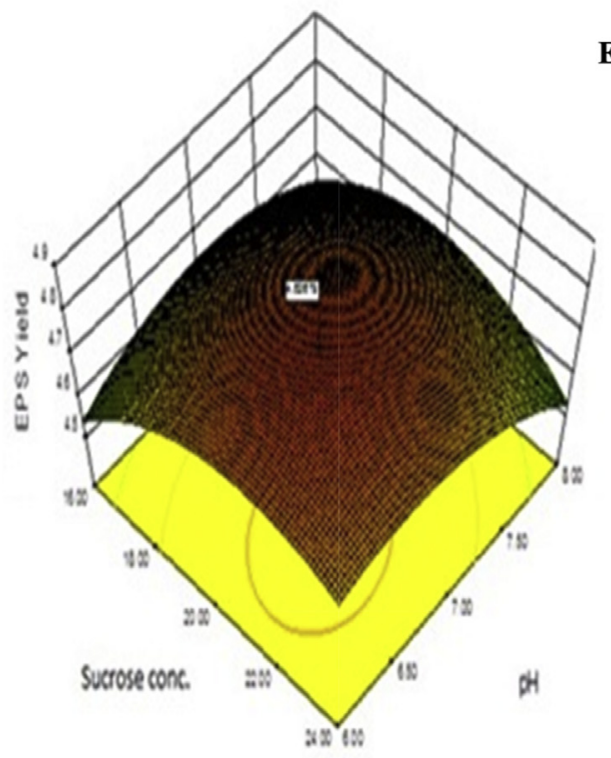

E
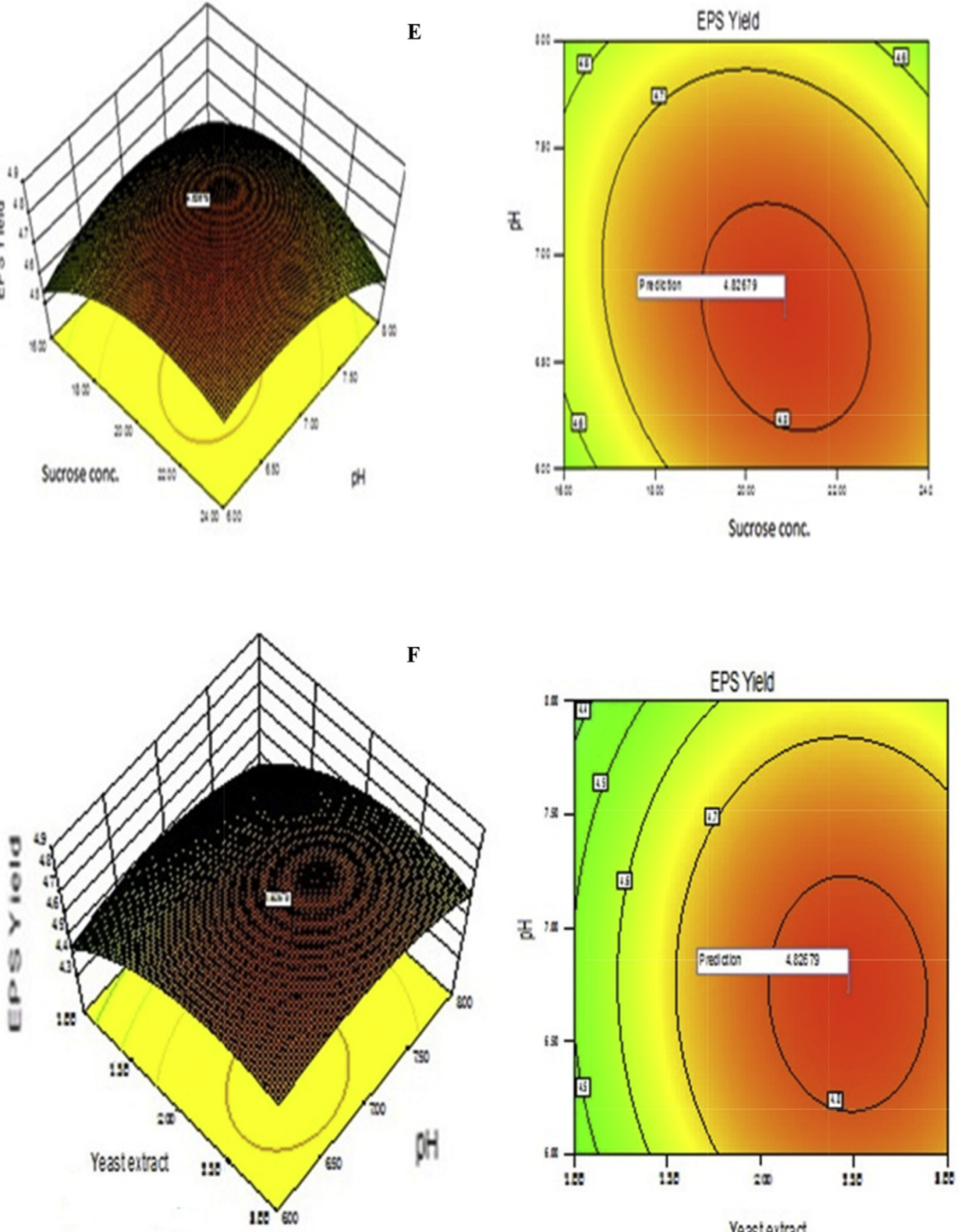

Yezstextrad.

Fig. 3. (continued) 


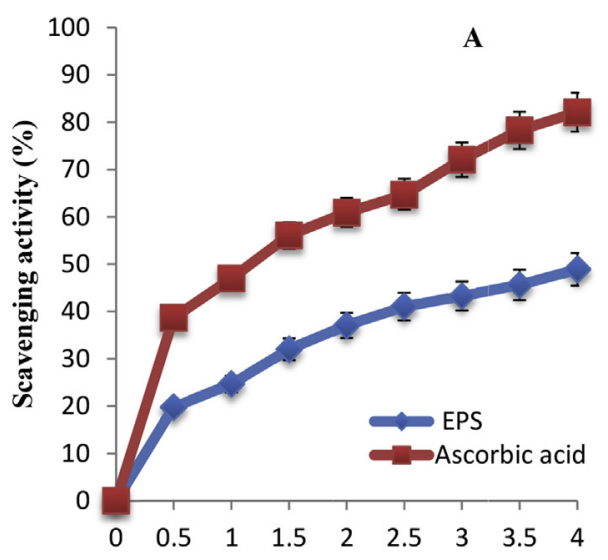

Concentration $(\mathrm{mg} / \mathrm{mL})$
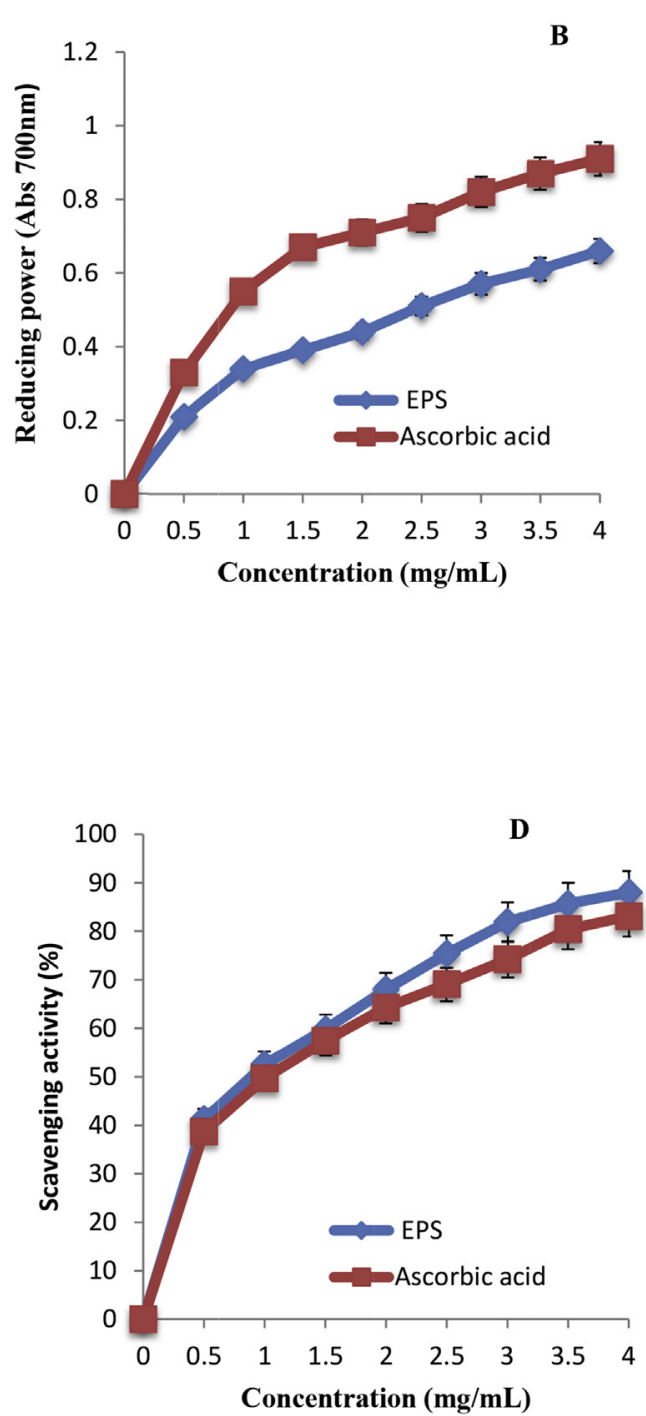

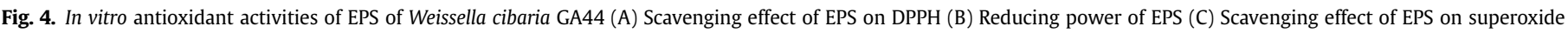
anion radical and (D) Scavenging effect of EPS on hydroxyl radical. The results are represented as mean \pm SD of triplicates.

that the mathematical model was suitable for the simulation of EPS production.

\subsection{Assay of antioxidant activities}

We assayed the antioxidant potential of the partially purified EPS-GA44. The EPS demonstrated significantly moderate antioxidant capacities in a dose-dependent manner in various in vitro models such as DPPH radical scavenging activity, reducing power assay, superoxide anion and hydroxyl radical scavenging activity and was compared with the control ascorbic acid.

\subsubsection{DPPH radical scavenging activity}

Fig. 4A showed the DPPH radical scavenging capacity of partially purified EPS from $W$. cibaria GA44 and the standard compound ascorbic acid. The scavenging activity of the EPS and ascorbic acid increases as their concentration increases, i.e. at low and high concentrations; $0.5 \mathrm{mg} / \mathrm{mL}$ (19.8\% and 38.7\%) and $4 \mathrm{mg} / \mathrm{mL}$ (48.9\% and $82.1 \%$ ) were obtained for the EPS and ascorbic acid respectively. Li et al. (2014) reported dose-dependent DPPH free radical scavenging activity of crude EPS from $L$. helveticus MB2-1. Similarly, other researchers have reported strong and concentrationdependent antioxidant activities in EPS from LAB (Xu et al., 2010; Zhang et al., 2013).

\subsubsection{Reducing power assay}

During the assay of reducing power, the capability of antioxidant compounds to reduce $\mathrm{Fe}^{3+}$ /ferricyanide complex to its ferric form was monitored by absorbance of Perl's Prussian blue formation at $700 \mathrm{~nm}$ (Chung, Chang, Chao, Lin, \& Chou, 2002). The reducing power of EPS-GA44 increases at higher EPS concentration (Fig. 4B). The EPS revealed its potential antioxidant activity, but relatively lower than ascorbic acid which is the standard antioxidant used.

\subsubsection{Superoxide anion scavenging activity}

Superoxide anions are active free radical precursors that can react with biological macromolecules and have the potential to cause tissue damage (Pan \& Mei, 2010). The scavenging activity of the EPS and ascorbic acid on superoxide radicals are shown in Fig. 4C. At the different concentrations tested $(0.5-4 \mathrm{mg} / \mathrm{mL})$, the scavenging activity of the EPS and ascorbic acid increased with increase in concentration. At $4 \mathrm{mg} / \mathrm{mL}$ concentration, the 
scavenging activity of the EPS and the ascorbic acid was $77.1 \%$ and $83.1 \%$ respectively.

\subsubsection{Hydroxyl radical scavenging activity}

Hydroxyl radicals are responsible for the oxidative injury of biomolecules (Gülçin, 2006). The scavenging activity on hydroxyl radical of the EPS and ascorbic acid are shown in Fig. 4D. The scavenging effects of EPS and ascorbic acid increases with increase in their concentrations. At the concentration of $4 \mathrm{mg} / \mathrm{mL}$, the scavenging capability of the ascorbic acid was $83 \%$; however, the activity of the EPS reached up to $88 \%$. This result indicates that the EPS has stronger scavenging activity on hydroxyl radical compared to that of the standard antioxidant used.

\section{Conclusion}

Exopolysaccharides from LAB have potential for development as functional food ingredients or food additives having both economic and health benefits. In the present work the optimum factors and culture conditions for production of EPS by lactic acid bacterium Weissella cibaria GA44 were identified. In-vitro antioxidant assay showed strong antioxidant properties, especially scavenging of superoxide anions and hydroxyl radicals. These results suggest that EPS from Weissella cibaria GA44 may be a better alternative natural source with potential antioxidant activity, and as well as healthy food grade adjunct culture.

\section{Conflict of interest}

\section{Authors declare that there are no conflicts of interest whatsoever.}

\section{Acknowledgements}

The authors would like to thank Dr. D.D. Joshi (Natural Product Chemistry Laboratory, IBSD, Imphal), for his suggestion and kind help in the TLC analysis. Adesulu-Dahunsi A.T. would like to acknowledge the World Academy of Sciences (TWAS), Trieste, Italy and the Department of Biotechnology (DBT), Ministry of Science and Technology, India, for the award of a postgraduate research fellowship. The authors would also like to acknowledge the assistance of Ogunsakin A.O. (FMBCT Department, CSIR, Mysore, India) for the FT-IR analysis.

\section{Appendix A. Supplementary data}

Supplementary data related to this article can be found at http:// dx.doi.org/10.1016/j.lwt.2017.09.013.

\section{References}

Abdhul, K. Ganesha, M., Shanmughapriya, S., Kanagavel, M., Anbarasu, K., \& Natarajaseenivasana, K. (2014). Antioxidant activity of exopolysaccharide from probiotic strain Enterococcus faecium (BDU7) from Ngari. International Journal of Biological Macromolecules, 70, 450-454.

Adesulu-Dahunsi, A. T. Sanni, A. I., \& Jeyaram, K. (2017). Rapid differentiation among Lactobacillus, Pediococcus and Weissella species from some Nigerian indigenous fermented foods. LWT- Food Science and Technology, 77, 39-44.

Badel, S., Bernardi, T., \& Michaud, P. (2011). New perspectives for Lactobacilli exopolysaccharides. Biotechnology Advance, 29, 54-66.

Balakrishnan, B., Prasad, B., Rai, A. K., Velappan, S. P., Subbanna, M. N., \& Narayan, B. (2011). In-vitro antioxidant and antibacterial properties of hydrolyzed proteins of delimed tannery fleshings: Comparison of acid hydrolysis and fermentation methods. Biodegradation, 22, 287-295.

Baruah, R., Maina, N. H., Katina, K., Juvonen, R., \& Goyal, A. (2017). Functional food applications of dextran from Weissella cibaria RBA12 from pummelo (Citrus maxima). International Journal of Food Microbiology, 242, 124-131.

Chung, Y. C., Chang, C. T., Chao, W. W., Lin, C. F., \& Chou, S. T. (2002). Antioxidative activity and safety of the $50 \%$ ethanolic extract from red bean fermented by
Bacillus subtilis IMR-NK1. Journal of Agriculture and Food Chemistry, 50, 2454-2458.

De Vuyst, L., \& Degeest, B. (1999). Heteropolysaccharides from lactic acid bacteria. FEMS Microbiology, 23, 153-177.

Degeest, B., Vaningelgem, F., \& De Vuyst, L. (2001). Microbial physiology, fermentation kinetics, and process engineering of heteropolysaccharide production by lactic acid bacteria. International Dairy Journal, 11, 747-757.

Dilna, S. V., Surya, H., Aswathy, R. G., Varsha, K. K., \& Sakthikumar, D. N. (2015). Characterization of an exopolysaccharide with potential health benefit properties from a probiotic Lactobacillus plantarum RJF4. LWT Food Science Technology, 64, 1179-1186.

Dubois, M., Gilles, K., Hamilton, J., Rebers, P., \& Smith, F. (1956). Colorimetric methods for determination of sugars and related substances. Annals of Chemistry, 28, 350-356.

Emerit, J., Edeas, M., \& Bricaire, F. (2004). Neurodegenerative diseases and oxidative stress. Biomedical Pharmacology, 58, 39-46.

Fukuda, K., Shi, T., Nagami, K., Leo, F., Nakamura, T., Yasuda, et al. (2009). Effects of carbohydrate source on physicochemical properties of the exopolysaccharide produced by Lactobacillus fermentum TDS030603 in a chemically defined medium. Carbohydrates Polymer, 79, 1040-1045.

Gülçin, I. (2006). Antioxidant and antiradical activities of L-carnitine. Life Science, $78,803-811$.

Hallemeersch, I., De Baet, S., \& Vandamme, E. J. (2002). Exopolysaccharides of lactic acid bacteria. Weinheim: Biopolymers Wiley VCH.

Imran, M. Y. M., Reehana, N., Jayaraj, K. A., Ahamed, A. Z. P., Dhanasekarana, D., Thajuddina, N., et al. (2016). Statistical optimization of exopolysaccharide production by Lactobacillus plantarum Statistical optimization of exopolysaccharide production by Lactobacillus plantarum NTMI05 and NTMI20. International Journal of Biological Macromolecules, 93, 731-745.

Ismail, B., \& Nampoothiri, K. M. (2010). Production, purification and structural characterization of an exopolysaccharide produced by a probiotic Lactobacillus plantarum MTCC 9510. Archive of Microbiology, 192, 1049-1057.

Kajala, I., Shi, Q., Nyyssölä, A., Maina, N. H., Hou, Y., \& Katina, K. (2015). Cloning and characterization of a Weissella confusa dextransucrase and its application in high fibre baking. PLoS ONE, 10, 0116418.

Kanmani, P., Kumar, R. S., Yuvaraj, N., Paari, K. A., Pattukumar, V., \& Arul, V. (2011). Production and purification of a novel exopolysaccharide from lactic acid bacterium Streptococcus phocae PI80 and its functional characteristics activity in vitro. Bioresources Technology, 102, 4827-4833.

Kim, D., Robyt, J. F., Lee, S. Y., Lee, J. H., \& Kim, Y. M. (2003). Dextran molecular size and degree of branching as a function of sucrose concentration, $\mathrm{pH}$ and temperature of reaction of Leuconostoc mesenteroides B512FMCM dextransucrase. Carbohydrates Research, 338, 1183-1189.

Kris-Etherton, P. M., Hecker, K. D., Bonanome, A., Coval, S. M., Binkoski, A. E., \& Hilpert, K. F. (2002). Bioactive compounds in foods: Their role in the prevention of cardiovascular disease and cancer. Medicine, 113, 71-88.

Laws, A. P., \& Marshall, V. M. (2001). The relevance of exopolysaccharides to the rheological properties in milk fermented with ropy strains of lactic acid bacteria. International Dairy Journal, 11, 709-722.

Li, Z., Jiang, A., Yue, T., Wang, J., Wang, Y., \& Su, J. (2013). Purification and identification of five novel antioxidant peptides from goat milk casein hydrolysates. Journal of Dairy Science, 96, 4242-4251.

Li, W., Ji, J., Rui, X., Yu, J., Tang, W., Chen, X., et al. (2014). Production of exopolysaccharides by Lactobacillus helveticus MB2-1 and its functional characteristics in vitro. LWT - Food Science Technology, 59, 732-739.

Liu, C., Lu, J., Lu, L., Liu, Y., Wang, F., \& Xiao, M. (2010). Isolation, structural characterization and immunological activity of an exopolysaccharide produced by Bacillus licheniformis 8-37-0-1. Bioresources Technology, 101, 5528-5533.

Liu, J., Luo, J., Ye, H., Sun, Y., Lu, Z., \& Zeng, X. (2009). Production, characterization and antioxidant activities in vitro of exopolysaccharides from endophytic bacterium Paenibacillus polymyxa EJS-3. Carbohydrates Polymers, 78, 275-281.

Liu, F., Ooi, V. E., \& Chang, S. T. (1997). Free radical scavenging activities of mushroom polysaccharide extracts. Life Science, 60, 763-771.

Liu, J. R., Wang, S. Y., Lin, Y. Y., \& Lin, C. W. (2002). Antitumor activity of milk, kefir and soya milk kefir in tumor bearing mice. Nutrition Cancer, 44, 183-187.

Lowry, O. H., Rosebrough, N. J., Farr, A. L., \& Randall, R. J. (1951). Protein measurement with the Folin phenol reagent. Journal of Biological Chemistry, 193, 265-275.

Macedo, M. G., Lacroix, C., Gardner, N. J., \& Champagne, C. P. (2002). Effect of medium supplementation on exopolysaccharide production by Lactobacillus rhamnosus RW 9595M in whey permeate. International Dairy Journal, 12, 419-426.

Malang, S. K., Maina, N. H., Schwab, C., Tenkanen, M., \& Lacroix, C. (2015). Characterization of exopolysaccharide and ropy capsular polysaccharide formation by Weissella. Food Microbiology, 46, 418-427.

Melov, S., Ravenscroft, J., Malik, S., Gill, M. S., Walker, D. W. \& Clayton, P. E. (2000). Extension of life-span with superoxide dismutase/catalase mimetics. Science, 289, 1567-1569.

Pan, D., \& Mei, X. (2010). Antioxidant activity of an exopolysaccharide purified from Lactococcus lactis subsp. lactis 12. Carbohydrates Polymers, 80, 908-914.

Patel, S., Majumder, A., \& Goyal, A. (2012). Potentials of exopolysaccharides from lactic Acid bacteria. Indian Journal of Microbiology, 52, 3-12.

Rai, A. K. Jini, R., Swapna, H. C., Baskaran, V., Sachindra, N. M., \& Bhaskar, N. (2011) Application of native lactic acid bacteria for fermentative recovery of lipids and proteins from fish processing waste: Bioactivities of fermentation products. 
Journal of Aquatic Food Production Technology, 20, 32-44.

Raza, W., Makeen, K., Wang, Y., Xu, Y., \& Oirong, S. (2011), Optimization, purification, characterization and antioxidant activity of an extracellular polysaccharide produced by Paenibacillus polymyxa SQR-21. Bioresources Technology, 102, 6095-6103.

Sajna, K. V., Sukumaran, R. K., Gottumukkala, L. D., Jayamurthy, H., Dhar, K. S., \& Pandey, A. (2013). Studies on structural and physical characteristics of a novel exopolysaccharide from Pseudozyma sp. NII 08165. International Journal of Biological Macromolecules, 59, 84-89.

Sarwat, F. Q., Aman, S. A., \& Ahmed, N. (2008). Production and characterization of a unique dextran from an Indigenous Leuconostoc mesenteroides CMG713. International Journal of Biological Science, 4, 379-386.

Savadogo, A. C. Ouattara1, A. T, Savadogo, P. W., Barro, N. Ouattara, A. S. \& Traore, A. S. (2004). Identification of exopolysaccharides-producing lactic acid bacteria from Burkina Faso fermented milk samples. African Journal of Biotechnology, 3, 189-194.

Seo, E. J., Yoo, S. H., Oh, K. W., Cha, J., Lee, H. G., \& Park, C. S. (2014). Isolation of an exopolysaccharide-producing bacterium, Sphingomonas sp. CS101, which forms an Unusual Type of sphingan. Bioscience, Biotechnology, and Biochemistry, 68, $1146-1148$.
Shene, C., \& Bravo, S. (2007). Whey fermentation by Lactobacillus delbrueckii subsp. bulgaricus for exopolysaccharide production in continuous culture. Enzyme, Microbiology and Technology, 40, 1578-1584.

Wang, Y., Li, C., Liu, P., Ahmed, Z., Xiao, P., \& Bai, X. (2010). Physical characterization of exopolysaccharide produced by Lactobacillus plantarum KF5 isolated from Tibet Kefir. Carbohydrates Polymer, 82, 895-903.

Wang, J., Zhang, Q., Zhang, Z., \& Li, Z. (2008). Antioxidant activity of sulfated polysaccharide fractions extracted from Laminaria japonica. Biological Macromolecules, 42, 127-132.

Wang, J., Zhao, X., Tian, Z., Yang, Y., \& Yang, Z. (2015). Characterization of an exopolysaccharide produced by Lactobacillus plantarum YW11 isolated from Tibe Kefir. Carbohydrates Polymer, 125, 16-25.

Welman, A. D., \& Maddox, I. S. (2003). Exopolysaccharides from lactic acid bacteria: Perspectives and challenges. Trends in Biotechnology, 21, 269-274.

Xu, R., Ma, S., Wang, Y., Liu, L., \& Li, P. (2010). Screening, identification and statistic optimization of a novel exopolysaccharide producing Lactobacillus paracasei HCT. African Journal of Microbiology Research, 4, 783-795.

Zhang, L., Liub, C., Li, D., Zhaoa, Y., Zhanga, X., Zenga, X., et al. (2013). Antioxidant activity of an exopolysaccharide isolated from Lactobacillus plantarum C88. International Journal of Biological Macromolecules, 54, 270-275. 